\title{
Servicing Map Users at Aalborg University Library
}

\author{
by BILL STEVENSON
}

This is intended as a short discourse to explain the current policies for the development and management of the Map Collection, and for the provision of services, at Aalborg University Library, Denmark.

\section{MAPS AND ATLASES AS A LANGUAGE OF SCIENCE AND SOCIETY}

In the early 1960s, I attended a lecture at Edinburgh University in which Professor James Wreford Watson delivered one of his many provocative ideas on the Origins of Geography.

Geography, he said, is probably the oldest science which is known to Man. He continued with an account of our ancestors in the Older Stone Age with their concern for kin, hearth and territory as central themes for their sustenance as hunters and gatherers. Later, he modified his claim. Unspoken fear, he said, provided irrational Religion. Man's awareness developed by asking questions. Why? gave him Philosophy, What? gave him Physics, Where? gave him Geography and Where from? gave him History. These are still the foundation stones of our understanding of the World and our rôle in it.

The order is debatable, but concern for survival must have given Geography a primary position at an early stage. The beginning of Cartography was possibly the memory of an Early Man's understanding of Geography being expressed to his kin and his inheritors, as a contribution to securing their future.

From there, it was a relatively short process to realise that Cartography is a natural extension of the language which we use to provide answers to these and other questions about the World in which we live. Maps and atlases became a media to express, and to analyse, our thoughts, knowledge and 
experiences of place, space, boundaries and direction. Later, they became the tools of earth sciences, warfare, government, politics, economics, travel, urban and regional planning, commerce, etc., to express place, space, boundaries, movement and relationships. As an essential tool to record, to relate, to correlate and to plan our activities and our environment, Cartography has been our theory, method, technique and our implement to describe the World and ourselves in it.

Maps are described as the product of Cartography. Cartography changes and maps follow. Voyages of discovery and marine navigation both demanded and produced maps and charts. Advanced trigonometry and improved optics provided for regional, national and continental surveying and mapping. Political and economic systems required registration of people, activities and production as well as the construction of infrastructures. Photogrammetry and remote sensing improved our methods of survey and the extent of our cartographic activities to a global range. Computers aided the volume and speed of the registration of data, as well as its processing, display and distribution. Satellites have given us continuous surveys and instant reference. Digital cartography provides new media and new uses. It also provides for new users.

\section{MAP COLLECTION IN AALBORG UNIVERSITY LIBRARY}

The map collection is located in the Main Library at Langagervej 2, which is situated on the University's main campus, about six kilometres from the city centre, with reasonable public transport access. It is an open collection and is accessible during the Library's normal opening hours (Monday to Thursday 9.00 - 18.00, Friday 9.00 - 15.00, open throughout the year except on Public Holidays). It is intended that the map collection and its services are available on a self-help basis, but requests for assistance (bibliographical or technical) may be made to the librarian at the local information desk or to the map librarian.

Aalborg University Library serves, primarily, the library and information needs of Aalborg University, but it is also the academic and scientific library for the whole of North Jutland. This region contains a number of higher and vocational educational establishments, administrative authorities, research and development-based industries, as well as museums and cultural associations. The Library is open to the general public, who can register as users with the same rights and obligations as the University's own users. 
The Library is the main research centre for land surveying in Denmark, on account of the University's monopoly over the education of graduates for the surveying profession. This accounts for the many research activities involving geodesy, surveying, photogrammetry, remote sensing, cartography, geographical information systems, geographical positioning systems and related subject areas, as well as within the fields of regional and urban planning, land registration and management, development planning, architecture, economics, history, culture, building construction, civil engineering, natural resource management, environmental science, etc.

The aim of the map collection is to function as a study collection for students, teachers and research staff in land surveying and for the land surveying profession. It also caters for other teaching, research and professional activities concerning survey, measurement, monitoring of spatial aspects of situation and distribution, land use analysis, physical planning, etc., as well as providing general geographical reference material for the University, other educational and research establishments, public authorities, private companies, organisations and private citizens.

Advanced booking or appointments are not necessary in order to use the map collection, unless the material in question is particularly old, valuable or fragile, and has to be fetched from storage. Occasionally, there can be a short waiting time to use the cartographic workstations and the GIS-workstation. However, it is possible to book any of these workstations in advance.

The map collection is a reference collection and the material is usually not available for loan. However, in certain cases it is possible to borrow items via inter-library loan for use in another library's reading room. The University's students and staff may also borrow some types of material for photocopying, scanning or photography where special equipment is required, which is not available in the Library.

\section{CONTENTS OF THE MAP COLLECTION}

The contents of the map collection are largely of recent date - i.e. from the twentieth century, with the main emphasis on the last thirty years, but with an increasing number (over 100) of reproduction maps (colour facsimile and large format photocopies) of Denmark, Scandinavia and other European areas from earlier periods, in order to show the subject's development and change. Both the map collection and the related cartographic book collection contain 
historical material (original and copies), for the illustration of the history of Danish and international mapping and cartography, and cartographic bibliographies.

The map collection contains both atlases and map sheets - on paper (flat and folded), CD-ROM, diskettes or online, and some aerial photographs (local, national and international) on paper and CD-ROM. It includes almost 1,500 titles - including atlases (over 600), map series, cartographic bibliographies, cartographic histories, etc. Atlases are stored on customised and standard shelving; map sheets are stored in two vertical and six horizontal steel map cases (with 62 drawers), and electronic maps and other applications are stored in standard containers or installed on workstation hard drives.

The cartographic book collection contain more than 2,000 titles (about 1850 books and 150 journals) within the field of cartographic history, cartographic theory, methods and techniques (including land survey, photogrammetry, remote sensing, GIS (geographic information systems) and GPS (geographic positioning systems), etc.

\section{TYPES OF CARTOGRAPHIC MATERIAL IN THE LIBRARY}

The cartographic material which is required by users in Aalborg University Library includes books, periodicals, atlases, map sheets, reproductions, photographs, photocopies, scanned files, graphic files, datasets, programs, etc., on the following themes:

- cartography as the technical production of maps,

- cartography as the study of maps and their uses, and

- maps as the presentation of spatial information (including aerial and satellite photographs).

If we concentrate on maps as objects, we have:

- the maps which we have in our collection as hard copy;

- the computer programs which we have in our collection in order to process data and produce maps;

- the datasets in our collection, which can be processed into maps;

- the opportunity to download online datasets which can be processed into maps; 
- the maps which we can find and peruse online;

- the maps which we can find and download from online sources.

These maps can be examined as hard copy or as electronic media, and they can be converted from the one medium into the other by means of the technology which is present in the Library.

\section{1) Maps and Atlases as Sheets and Books}

1a) The collection and management of hard copy maps and atlases in the Library is a well-established practice. Aalborg University Library has had a computerised catalogue since 1976 and an online catalogue since the early 1980s. This contains bibliographic records of all our cartographic material in danMARC format. The Universal Decimal Classification (UDC) is used to classify all library material, with the addition of controlled and uncontrolled terms. Most of the maps and atlases are reference material, but a few are available for general loan, and even some of the reference material may be borrowed overnight for perusal or for photocopying, photographing, scan-ning, etc.

The online catalogue is called Auboline which is also an integrated part of Danbib, the Danish online common catalogue for most of the academic and special libraries in Denmark. Auboline has a Danish and an English language search interface, and the records use the language of the material for most of the bibliographical information. However, the indexing terms are in Danish.

\section{2) Maps and Atlases as Electronic Material}

2a) The Library has purchased a number of digital cartographic applications containing astronomical atlases, world and national atlases, national map series; thematic atlases and maps, including historical atlases, journey and other planning atlases, statistical atlases, etc. These have been supplied on diskettes or on CD-ROM and are installed on the hard disks of one of our cartographic workstations, or may be collected from the information desk to be used on the workstations.

All of these applications are included as records in Auboline and Danbib, but may only be used on the cartographic workstations, which, for 
security reasons, are not connected to the library network and thus not available via the Internet.

2b) The Library has also acquired a number of Geographical Information System (GIS) programs and GIS datasets which are either installed on the hard disk of the GIS workstation or can be collected from the local information desk. All of these programs and datasets are included as records in Auboline and Danbib, but may only be used on the GIS workstation, which is connected to the library network and thus it is possible to download other material from WWW sources. However, for security reasons, it is not possible to gain external access via the Internet, or from other workstations on the local network, to the GIS workstation.

2c) The Library has catalogued records of „interesting links” to external URLs in a Virtual Library. These links are systematised in about thirty subject profiles which are also search terms to identify related or overlapping profiles. In the case of URLs which are relevant to maps, mapping, cartography, etc., these are identified in the profiles „Geography”, „Land Surveying and Management” and „Physical Planning”. These profiles contain not only access to cartographic sources but also to electronic periodicals and recent Library accessions for related fields of interest.

These Virtual Library records are not catalogued in Auboline or UDC classified, but are indexed in the Virtual Libraries database, which is accessed via the Library's homepage.

2d) The Library has also catalogued records of ,interesting links” to external URLs in a database (Internet Links or NetRef) which is integrated in Auboline, but which can be separately identified for searching. These links are not classified in UDC, but use as profiles many of the same sixty controlled and uncontrolled terms as in UDC, but in Danish e.g. for maps, mapping, cartography, etc., the Danish controlled terms "Geodæsi”, „Geografi”, „Kartografi”, „Planlægning” and „Landmålingsvæsen” are relevant. These profiles contain not only cartographic sources but also other aspects of their subjects' fields of interest.

These materials provide for most of the current daily user needs. Thus, the services provided by the map collection and by the Main Library in which it is situated act as an interface between the diversity of the users and the diversity of the available sources. 


\section{CO-OPERATION WITH THE UNIVERSITY}

Aalborg University's Institute for Development and Planning, which has responsibility for the research and teaching of Land Surveying, Land Management and Physical Planning of all types, has established a Geodata Library for its internal use. Negotiations have started between the Institute and the Library for a service outlet from the Geodata Library to the rest of the University and, hopefully, to external users.

This would involve establishing a connection between the Institute's server and one or more workstations, or a netserver, in the Library in order to provide access to material which the Institute has acquired by purchase, gift or contract, or to which it has access.,. The source of this material and the copyright limitations may necessitate a user differentiation which must be secured by password access, e.g. for:

A) a group of cartographic products and facilities which may only be used for non-commercial purposes by the staff and students of the University;

B) a group of cartographic products and facilities which may be made available to other users but where use is registered to a name;

C) a group of cartographic products and facilities which may be made available to other users as a public service.

Amongst the items which are planned to be covered by this co-operative venture, subject to eventual third-party agreement, are

- Danish topographical digital map series $(1: 25,000,1: 50,000,1: 100,000$, 1:200,000, 1:500,000 and 1:2,000,000) with output possibilities to GIS applications. This will replace the present arrangement where the Library has to make a separate purchase.

- Danish digital cadastral (land registration) maps, land ownership register and benchmark register

- National digital elevation model

- New series of the Danish 1:10,000 digital maps with 40 different layers (topographic information, hydrography, land use, infrastructure, place names, administrative boundaries, etc.) which are suitable for CAD and GIS purposes as raster or vector maps.

- Address and roads database containing the geographical references of all postal addresses in Denmark 
- Digital technical maps of urban areas within the jurisdiction of Aalborg Local Authority

- Digital technical maps of rural areas within the jurisdiction of Aalborg Local Authority

- Digital orthographic aerial photographs for Aalborg and other local authority areas

- Diverse digital maps of areas with limitations on land use in the North Jutland Region

- Digital soil type maps from the National Geological Survey

- The National Buildings and Housing Register (age, type, usage, building materials, condition, ground and building valuation, present owner, etc. of all buildings with their postal and land register addresses), Ownership Register and Planning Register.

It is hoped, when this co-operative arrangement is in operation, that it will be possible to provide external access via the University network and Internet to those materials which are not affected by copyright, contract or licence limitations.

\section{CARTOGRAPHIC WORKSTATIONS}

The cartographic workstations may be used to display and process the Library's collection of about fifty electronic cartographic application programs which include astronomical atlases, world and national atlases, national map series, thematic atlases, including historical atlases, journey and other planning atlases, statistical atlases, etc. Some of the cartographic programs have already been installed on the workstations, while others are accessible on CDROMs, which may be borrowed from the local information desk and used on the workstations. The workstations' menus provide information on whether the program in question is already installed or has to be collected. The workstations enable the display of atlases and maps and also the production of customised maps using installed programs, such as Digital Chart of the World (DCW) for DOS. DCW enables library users to produce their own maps for all parts of the world. The GIS-programme ArcView 3.0 is also installed for public use. 
Cartographic workstation no. 1 is a Pentium II PC with a 3.75 gb hard disk, $64 \mathrm{mb}$ RAM and $4 \mathrm{mb}$ video RAM, and a 3.5" disk drive, CD-ROM drive and $6 \mathrm{CD}$ multi-drive are installed. The operating system is Windows 98.

Cartographic workstation no. 2 is a $486 \mathrm{PC}$ with a $1.05 \mathrm{mb}$ hard disk, $32 \mathrm{mb}$ RAM and 2 mb video RAM, and a 3.5" disk drive, CD-ROM drive and 6CD multi drive are installed. The operating system is Windows 3.11 (and MSDOS 6.22). Compression/decompression programs have been installed along with PhotoPaint 5.0.

The two cartographic workstations, for security reasons, do not have network connections. It is hoped that this can be remedied in the near future

\section{GIS WORKSTATION}

The Library has a GIS workstation where the GIS (Geographic Information System) program ArcView 3.0 (including Avenue and ESRI Maps \& Data) has been installed for public use. More programs have been installed for testing among them Landscape Explorer 3.5, Visual Terrain 98.0.1, Visual Animator 98.0.2, 3DEM Raytrace and MS Excel mapping.

The workstation thus provides opportunities to make customised special maps and spatial presentations via the installed programs, which may be used to produce and edit maps from all parts of the world, as well as to produce animated maps. DCW (Digital Chart of the World - Windows version) has been installed on the multi drive and may be used via ArcView

The workstation has a network connection which provides the added opportunity of downloading additional application programs, cartographic files and data files using the installed browser (Internet Explorer 3.02). There is at present no external access to the GIS workstation, but it is hoped that this may be remedied in the near future, possibly in connection with the Library's co-operation with the University, as described earlier.

The GIS workstation is a K6 PC with a 0.6 gb hard disk, 64 mb RAM and 4 $\mathrm{mb}$ video RAM. The operating system is Windows NT 4.0. It has a 3.5" floppy disk drive, CD-ROM drive, 6CD multi-drive and an Iomega 100 zipdrive. Compression/decompression programs have been installed along with PhotoShop 4.0. 


\section{PRINTING AND COPYING FACILITIES}

An HP DeskJet 1100C colour printer (A4 \& A3) has been installed for the cartographic workstations. It may be used with both workstations by means of a switching box.

An HP DesignJet 350C colour plotter/printer (A4 - A0) and an HP ScanJet 4P scanner (A4+) have been installed for the GIS workstation.

A4 and A3 prints from the colour printer and the plotter/printer are free of charge, but there is a fee for larger sized prints from the plotter to cover the cost of the colour cartridges.

Use of the HP ScanJet $4 p$ scanner is available to scan all map material without charge.

Maps and data files may also be copied from the cartographic workstations and the GIS workstation to 3.5 " disks $(720 \mathrm{~kb}$ or $1.44 \mathrm{mb})$ or via the zipdrive disks $(100 \mathrm{mb})$ at the GIS workstation. The zipdrive disks can be read on most CD-ROM drives. All diskettes and disks must be bought at the Library's main desk. Only disks which have been purchased from the Library are permitted to be used in any of the Library's workstations.

Photocopy machines (A4 and A3) with the possibility for enlargement and for reduction are also available. Copy cards may be bought at the Library's main desk.

\section{INTERNET ACCESS TO THE LIBRARY AND ITS CATALOGUE}

Aalborg University Library System - <http://www.aub.auc.dk/eaub/>

Auboline - <http://a500.aub.auc.dk:4505/ALEPH>

Virtual Libraries - <http://www.aub.auc.dk/>

InterNet Links/NetRef - <http://a500.aub.auc.dk:4505/ALEPH/SESSION40114/start/NETREF>

\section{Using Auboline}

The collection is arranged according to the Universal Decimal Classificationsystem (UDC) and catalogued in Auboline - the Library's online catalogue - 
and in DANBIB, which is the common online catalogue for Danish research and special libraries. Auboline is accessible online for those who are connected to the university network, and via Telnet and the Internet.

The search term „kortsamling” will find records of the material which is available in the map collection.

The search term „kartografiske arbejdsstation” will find records of the material which is available for use on the cartographic workstations.

The search term „GIS-arbejdsstation” will find records of the material which is available for use on the GIS workstation.

\begin{tabular}{|l|l|}
\hline UDC system & Relevant groups \\
\hline 528.4 & Topographic, technical and cadastral surveying \\
\hline 528.5 & Surveying instruments \\
\hline 528.7 & Photogrammetry \\
\hline 528.8 & Remote sensing \\
\hline 528.9 & Cartography \\
\hline 910.2 & Geographic technique (including GIS) \\
\hline 912 & Cartography, visual presentation of maps and atlases \\
\hline $912(01)$ & Cartographic bibliographies \\
\hline $912(091)$ & Historical cartography \\
\hline 912.43 & Map sheets \\
\hline $912.43(091)$ & Historical map sheets \\
\hline 912.44 & Atlases and map books \\
\hline $912.44(091)$ & Historical atlases and map books \\
\hline 912.45 & Globes \\
\hline
\end{tabular}

